IZA DP No. 10094

Impact of Ethnic Civil Conflict on Migration of Skilled Labor

Julie Christensen

Darius Onul

Prakarsh Singh

July 2016 


\title{
Impact of Ethnic Civil Conflict on Migration of Skilled Labor
}

\author{
Julie Christensen \\ Amherst College \\ Darius Onul \\ Amherst College \\ Prakarsh Singh \\ Amherst College \\ and IZA \\ Discussion Paper No. 10094
July 2016 \\ IZA \\ P.O. Box 7240 \\ 53072 Bonn \\ Germany \\ Phone: +49-228-3894-0 \\ Fax: +49-228-3894-180 \\ E-mail: iza@iza.org
}

Any opinions expressed here are those of the author(s) and not those of IZA. Research published in this series may include views on policy, but the institute itself takes no institutional policy positions. The IZA research network is committed to the IZA Guiding Principles of Research Integrity.

The Institute for the Study of Labor (IZA) in Bonn is a local and virtual international research center and a place of communication between science, politics and business. IZA is an independent nonprofit organization supported by Deutsche Post Foundation. The center is associated with the University of Bonn and offers a stimulating research environment through its international network, workshops and conferences, data service, project support, research visits and doctoral program. IZA engages in (i) original and internationally competitive research in all fields of labor economics, (ii) development of policy concepts, and (iii) dissemination of research results and concepts to the interested public.

IZA Discussion Papers often represent preliminary work and are circulated to encourage discussion. Citation of such a paper should account for its provisional character. A revised version may be available directly from the author. 
IZA Discussion Paper No. 10094

July 2016

\section{ABSTRACT}

\section{Impact of Ethnic Civil Conflict on Migration of Skilled Labor ${ }^{1}$}

We reevaluate the hypothesis and empirical result that ethnic civil wars lead to higher skilled emigration (Bang and Mitra, 2013). We develop a simple conceptual framework that predicts contrasting results depending upon if the economy is assumed to be agglomerating in skilled labor or non-agglomerating with network effects. In the latter case, non-ethnic wars may lead to higher skilled emigration. A regression model that accounts for the time-varying definition of migration and includes important explanatory variables shows that non-ethnic wars as opposed to ethnic wars may lead to more skilled emigration.

JEL Classification: J1, F2, O1

Keywords: civil war, emigration, brain drain, ethnic war, agglomeration, high-skilled migration

Corresponding author:

Prakarsh Singh

Department of Economics

Amherst College

P.O. Box 2201

Amherst, MA 01002-5000

USA

E-mail: psingh@amherst.edu

\footnotetext{
${ }^{1}$ We are thankful to two anonymous reviewers and to Susan Averett for their incisive comments, and to James Bang and Aniruddha Mitra for sharing their dataset with us. We are grateful to Sam Alpert for excellent research assistance. All errors are our own.
} 


\section{Introduction}

The subject of brain drain and skilled emigration has received considerable attention in recent decades. The emigration of skilled workers is thought to harm developing countries, where human capital is already scarce. One of the major causes of brain drain has been political instability often resulting from civil conflict. As internal conflict reduces the expected returns to educational investment, an educated person will have a higher incentive to migrate. However, there is little empirical evidence on the impact of civil conflict on the migration of skilled labor (an exception is Bang and Mitra, 2013). In this paper, we reevaluate the existing evidence with better data and a more conservative specification, and propose a new framework through which to view the analysis.

According to Sambanis (2001), civil conflict often occurs because of ethnic heterogeneity within a country, which appears to significantly increase the risk of civil war. ${ }^{2}$ These findings are in contrast to Fearon and Laitin (2003) who show that after controlling for per capita income, more ethnically or religiously diverse countries are no more likely to experience significant civil violence. They find that characteristics such as, poverty, political instability, rough terrain, and large populations play a significantly larger role in explaining civil violence than ethnic or religious characteristics (Fearon and Laitin, 2003). ${ }^{3}$

\footnotetext{
${ }^{2}$ Sambanis (2001) attempts to analyze any differences that may exist between ethnic and nonethnic civil wars and finds that political factors, such as the level of democracy, are more important than economic factors in causing ethnic civil war. Sambanis (2001) uses a rather strict criterion for coding a civil war as ethnic. In order to code as ethnic, the war must be "among communities (ethnicities) that are in conflict over the power relationship that exists between those communities and the state".

3 According to the well quoted definition of ethnic groups by Horowitz, "ethnic groups are defined by ascriptive differences, whether the indicium is color, appearance, language, religion, some other indicator of common origin, or some combination thereof" (Horowitz, 1985). Fearon and Laitin acknowledge that there is a measurement problem with rigid classifications of ethnic,
} 
Overall, ethnic civil wars are correlated with greater intensity of violence (Eck, 2009), exhibit a greater likelihood of recurrence (Kreutz, 2010), and tend to be of greater duration (Kirschner, 2009). It would appear that because of these factors, ethnic civil wars would cause more harm to skilled human capital leading to their higher emigration. Indeed, this is the central result from Bang and Mitra's seminal paper (hereafter "BM"). However, it seems that no other paper has analyzed skilled and unskilled emigration based on a disaggregated data set of civil wars. In Section II, we postulate a simple framework to analyze the impact of a shock (here, ethnic or non-ethnic conflict), on the proportion of skilled migration and proportion of population that is educated. Our hypotheses predict contrasting results depending upon if the economy is assumed to be agglomerating in skilled labor or non-agglomerating with network effects. Section III introduces our data and empirical model. Section IV presents the results. Section V provides robustness checks and Section VI concludes.

\section{Conceptual Framework}

Assume a country has no skilled emigration if the entire population is educated. Also, as the share of the population becomes less educated, there is higher migration. We consider this to be an agglomerating economy, i.e., where there are increasing returns to scale from having an educated workforce. This is similar to the concept in Kremer's O-ring theory (Kremer, 1993) where one's marginal product depends upon other workers' marginal products in a complementary way. As the educated workforce goes down, there is an incentive to migrate. This is represented by a downward sloping curve with the vertical axis being share of migration that is skilled and horizontal axis being proportion of population that is educated. In this case,

non-ethnic, and mixed or ambiguous. Fearon and Laitin in their coding identified as much as $18 \%$ of their civil war data set as "mixed or ambiguous" (Fearon and Laitin, 2003). 
we consider two separate types of shocks: (1) an ethnic civil war and a (2) non-ethnic civil war. From existing empirical evidence, it can be assumed that an ethnic civil war would lead to a greater upward shift of the curve and we may move from an initial equilibrium point like A to a point like B as shown in Figure 1a for ethnic war and Figure $1 \mathrm{~b}$ for a non-ethnic war. These shifts show an increase in skilled migration for both types of wars, given a fixed level of proportion of educated people. However, as the destruction is greater in ethnic wars on average (and also because wars appear to last longer), we have represented a greater upward shift of the curve in the case of the ethnic war. Not only is there a direct exogenous impact on skilled migration as assumed in earlier work, but war is also likely to lead to lower educational attainment because of closure of schools, risk to life and lower returns to schooling. This has been found in Blattman, and Annan (2010), Chamarbagwalaand Morán (2011), Kecmanovic (2013), Singh and Shemyakina (2016), Swee (2009), and Walsh (2000). This would make the equilibrium point shift from $\mathrm{B}$ to $\mathrm{C}$ as shown in Figures 1a and $1 \mathrm{~b}$. Here, too, it can be assumed that the negative impact on proportion of educated people will be greater in ethnic wars. Thus, point $\mathrm{C}$ is further up (and with fewer educated people as a share of the total population) in this agglomerating economy with an ethnic civil war compared to a non-ethnic civil war. In the data, this type of economy would show a positive correlation between an ethnic war and skilled emigration.

In the second case, we consider an economy that is non-agglomerating and with network effects. Here, if there is a more educated workforce, the proportion of skilled migration goes up (increases in brain drain may occur either due to linkages or due to formation of an agglomeration cluster abroad). This can be represented by an upward sloping curve in the same framework as shown in Figures $2 \mathrm{a}$ and $2 \mathrm{~b}$. The effect of the ethnic and non-ethnic civil wars is to 
shift from initial point A to point B (a larger increase in proportion of skilled migration in an ethnic civil war as compared to a non-ethnic civil war for a given proportion of educated people). However, there is a second effect from point $\mathrm{B}$ to point $\mathrm{C}$ which may result in an ethnic war causing a lower proportion of skilled migration as compared to a non-ethnic war. Thus, the net effect of the type of war on proportion of skilled migration depends upon the underlying relationship between skilled migration and educated workforce (agglomerating or nonagglomerating).

\section{Empirical Model and Data}

We measure the impact of civil conflict on the emigration of high-skilled workers using the following equation:

$$
\text { High-skillijt }=\beta \text { Conflictijt }+\gamma Z_{i}+\mu P_{i t}+R_{j}+Y_{t}+\varepsilon_{i j t}
$$

The dependent variable, High-skill $l_{i j t}$, is the stock of high-skilled emigrants (those with 13 or more years of education) divided by the stock of total emigrants from country $i$ in region $j$ in year $t$ living in any of the six main OECD destination countries (the United States, Canada, Australia, France, Germany, and the UK). The dependent variable is compiled by Defoort (2008) and is available at 5-year intervals over the period 1975-2000, yielding six observations for each country. ${ }^{4}$

While BM uses conflict data from both the Political Instability Task Force (PITF) and the Uppsala Conflict Data Program (UCDP), we primarily utilize UCDP data and use PITF and Correlates of War (COW) data as robustness checks. We follow BM's coding of conflict

\footnotetext{
${ }^{4}$ This is in contrast to BM, who employ a time-fixed dependent variable. As seen in Figure A1, the positive correlation between proportion of high-skill emigrants and civil conflict is weakened substantially when BM's time-varying proportion of high-skill emigrants is used.
} 
variables and create dummy variables that take on a value of 1 if the country experienced a conflict within the past 5 years and a value of 0 otherwise. Both the UCDP data and PITF data are taken directly from the dataset that BM shared with us. In contrast to BM, our model includes a dummy variable for general civil conflict and a dummy variable for ethnic conflict. This specification tests whether ethnic conflict is significantly different than general conflict, as opposed to whether it is significantly different from no conflict. ${ }^{5}$

$R_{j}$ and $Y_{t}$ account for regional and year fixed effects. The matrix of country-level controls, $Z_{i}$, consists of fixed country characteristics. These include colonial origins, legal origins, and geography from Acemoglu et al. (2001). Because the dependent variable only accounts for emigration to the six main OECD countries, a country's geographic location and colonial and legal ties to OECD-6 countries may be important predictors of emigration and the selection rate. This is well documented in the brain drain literature (Docquier et al. 2007). To account for the effect of geography we include the median latitude and longitude of a country, as well as a dummy variable for whether a country is landlocked. We also include dummy variables for whether a country has legal or colonial origins with the OECD-6.

The time varying characteristics, $P_{i t}$, in source country include: (a) the natural logarithm of GDP per capita, population, and the CPI inflation rate from the World Development Indicators; (b) average years of education in each source country from Barro and Lee (2013); (c) the democracy-autocracy index from the Polity IV project; (d) dummy variables for type of political systems from the Database of Political Institutions (Beck et al., 2001); and (e) dummy variables for type of effective executive from the Cross-National Time Series Data Archive (Banks, 2010). Table 1 provides the summary statistics for all variables employed in our paper.

\footnotetext{
${ }^{5}$ Thanks to an anonymous reviewer for making this suggestion.
} 
In most of our specifications, we chose to omit one of BM's independent variables, total emigrants, as it is endogenous to the model. The total emigrants variable is the total foreign-born population residing in the OECD-6 from a particular country, which is also the denominator of the dependent variable. BM's justification for including this variable appears to be that it captures network effects, which have been shown to be an important determinant of migration flows. Diasporas are particularly important for unskilled emigrants because the network provides information and financial support, thereby lowering the cost of migration and assimilation and may also attract unskilled migrants via family reunification programs (Beine et al. 2010). However, this approach does not come without its own set of problems.

First, including the denominator of the left-hand side variable as a control variable on the right-hand side variable may bias the estimates as a classical measurement error in this variable now leads to a bias in an ambiguous direction over and above the attenuation bias associated with measurement error in a standard regression. It is likely that total emigrants is a noisy variable both over time and within countries. For other reasons why such regressions should be treated with caution, please see Firebaugh and Gibbs (1985). Therefore, as the total emigrants variable is endogenous to the model, we remove it from the regression except for column 3 in Tables 2 to 10 .

\section{Results}

In Table 2, the presence of civil conflict is positively correlated with the fraction of highly skilled emigrants, but the result is not statistically significant across a range of staggered controls. In Table 3, column (7), the presence of ethnic conflict increases the fraction of highly skilled emigrants by about 1 percentage point, but the result is not statistically significant. 
However, the presence of non-ethnic conflict (over and above peace) increases the fraction of highly skilled emigrants by about 4 percentage points and is statistically significant at the 5 percent level. These findings are quite different from those presented earlier in the literature because of time-varying definition of the dependent variable. However, they still support the argument that ethnic and non-ethnic wars are distinct phenomena (Sambanis 2001; ReynalQuerol 2002). These studies have argued that ethnic civil wars are fueled by political grievances, while non-ethnic civil wars are fueled by a lack of economic opportunity. As posited in the conceptual framework, however, we find that for a non-agglomerating economy, ethnic wars may lead to lower skilled emigration as compared to non-ethnic wars. This may occur because ethnic wars also endogenously change the proportion of educated people in the economy more than non-ethnic wars.

Table 4 tests for the impact of ethnic wars over and above general conflict and fails to find any additional significant effect. We also check if the impact is greater for medium-skill emigrants (those with 9-12 years of education) in Table 5. Here, too, we find that ethnic conflict has no additional positive impact on migration (without regional fixed effects and additional controls, the correlation is actually negative). Analogously, we find opposite effects of general conflict on proportion of low-skilled emigration in Table 6 suggesting that conflict (but not ethnic conflict) leads to greater high-skilled emigration (but not low-skilled emigration). ${ }^{6}$

\footnotetext{
${ }^{6}$ In order to test the robustness of our results, we carry out two types of checks. In Online Appendix Tables A1 and A2, we employ a dependent variable which is equal to the $\ln$ (Proportion of high-skill emigrants). We find results that are even stronger in suggesting that ethnic civil wars have no differential impact on high-skilled emigration (and the impact may be less as compared to non-ethnic conflict). Next, we consider two alternative sources of data for civil conflict other than UCDP. In Table A3, we use the PITF data and Table A4 employs Correlates of War (COW) data for measurement of conflict. All estimates are consistent with estimates in Tables 2, 3 and 4.
} 


\section{Mechanism Check}

In Tables 7 and 8, we propose a mechanism check for the greater negative impact of ethnic wars on years of education as compared to non-ethnic wars. According to our conceptual framework, if we did find a greater impact of non-ethnic wars on high-skill emigration, ethnic wars must also decrease the average years of education more than non-ethnic wars in a non-agglomerating economy with network effects. We find that ethnic wars do seem to lead to greater decreases in average years of education. In the most conservative specification (column (6) in both tables), ethnic wars appear to have twice as much of an impact on reducing years of education (on average 1 year) as compared to a non-ethnic war (on average half a year). Reasons for this may include the greater destruction of human and physical capital, the lowering of state capacity and enforcement institutions, lower returns to schooling, and longer-lasting ethnic wars. This is consistent with the existing evidence on the harmful effects of ethnic civil wars. We can conclude that in the case of the non-agglomerating economy with network effects, ethnic wars could have a lower impact on high-skill emigration as compared to non-ethnic wars both in theory and from empirical evidence. ${ }^{7}$

\section{Conclusion}

It has been suggested that ethnic civil wars should lead to greater high-skilled emigration in both theory and empirics (Bang and Mitra, 2013). We show through a simple conceptual

\footnotetext{
${ }^{7}$ We ran a regression with country fixed effects, which is presented as Appendix Table A5. As before, we find insignificant differential effects of ethnic civil wars but also insignificant effect of general conflict because the country fixed effects soaks up much of the variation $\left(\mathrm{R}^{2}\right.$ is 0.91$)$. As data on migration is updated every five years, there appears to be insufficient within-country variation available to be explained by the year and country-varying conflict data.
} 
framework that this may not be obvious as ethnic civil wars also simultaneously change the proportion of educated people in the economy. By accounting separately for the time-varying definition of the dependent variable, and by including other significant explanatory variables, the quantitative and qualitative results change significantly. Ethnic civil wars have insignificant effects on high-skilled emigration and across the most conservative specification effects are much less than those of non-ethnic wars. Results are robust to including regional and year fixed effects, and they stay insignificant after including geography, legal or colonial institutions. Finally, we also try alternative definition of the dependent variable and also measure the conflict variable through two different data sets. These robustness checks do not change the main narrative that ethnic civil wars do not appear to have a differential positive or significant effect on high-skilled emigration as compared to non-ethnic wars. Overall, we believe that the literature on conflict and emigration needs to be more deeply researched, both at a theoretical and an empirical level because it can provide us with predictions about human capital flight and more effectively tailor policy recommendations. 


\section{Work Cited}

Acemoglu, D., Johnson, S., Robinson, J.A., 2001. The Colonial Origins of Comparative Development: An Empirical Investigation. American Economic Review 91, 1369-1401. doi:10.1257/aer.91.5.1369

Austin, A., Dutt, S., 2015. Ethnic Diversity, Economic Institutions and Civil War: Theory and Empirics. Indian Journal of Economics and Business 14, 179-194. doi:http://ijeb.com/cms/issues/

Bang, James T., and Aniruddha Mitra. 2013. Civil war, ethnicity, and the migration of skilled labor. Eastern Economic Journal, 39(3): 387-401.

Banks, Arthur S. 2010. Cross-national Time-series Data Archive. Jerusalem, Israel: Databanks International.

Barro, Robert and Jong-Wha Lee. 2013. A New Data Set of Educational Attainment in the World. 1950-2010. Journal of Development Economics, 104: 184-198.

Beck, Thorsten, George Clarke, Alberto Groff, Philip Keefer, and Patrick Walsh. 2001. New Tools in Comparative Political Economy: The Database of Political Institutions. World Bank Economic Review, 15(1): 165-176.

Beine, Michel A., Frederic Docquier, and Caglar Ozden. 2010. Diasporas. Journal of Development Economics, 95(1): 30-41.

Besley, Timothy, and Torsten Persson. 2008. Wars and state capacity. Journal of the European Economic Association, 6(2 3): 522-530.

Blattman, C., \& Annan, J. (2010). The consequences of child soldiering. Review of Economics and Statistics, 92(4), 882-898 
Chamarbagwala, R., \& Morán, H. (2011). The human capital consequences of civil war: Evidence from Guatemala. Journal of Development Economics, 94(1), 1-61

Docquier, Frederic, Olivier Lohest, and Abdeslam Marfouk. 2007. Brain drain in developing countries. World Bank Economic Review, 21(2): 1-26.

Eck, Kristine. 2009. From Armed Conflict to War: Ethnic Mobilization and Conflict Intensification. International Studies Quarterly, 53(2): 369-388.

Esteban, Joan, and Debraj Ray. 2008. On the Salience of Ethnic Conflict. American Economic Review, 98(5): 2185-2202.

Fearon, J.D., 2004. Why Do Some Civil Wars Last so Much Longer than Others? Journal of Peace Research 41, 275-301.

Fearon, James, and David Laitin. 2003. Ethnicity, insurgency, and civil war. American political science review, 97(1): 75-90.

Firebaugh, Glenn, and Jack P. Gibbs. 1985. User's guide to ratio variables. American Sociological Review, 713-722.

Ghosn, Faten, Glenn Palmer, and Stuart Bremer. 2004. The MID3 Data Set, 1993-2001: Procedures, Coding Rules, and Description. Conflict Management and Peace Science, $21: 133-154$

Green, Elliott. Redefining Ethnicity. 2006. In 47th Annual International Studies Association Convention, March, San Diego, CA. Available online at http:personal.Ise.ac.uk/green/ISA.pdf.

Horowitz, D.L., 1998. Structure and Strategy in Ethnic Conflict.

Horowitz, D.L., 1985. Ethnic groups in conflict. Berkeley : University of California Press, c1985. 
Kecmanovic, M. 2013. The short-run effects of the Croatian war on education, employment, and earnings. Journal of Conflict Resolution, 57(6), 991-1010

Kirschner, Shanna A. 2009. Families and Foes: Ethnic Civil War Duration, Doctoral Thesis, Department of Political Science, University of Michigan.

Kremer, Michael. 1993. The O-Ring Theory of Economic Development. The Quarterly Journal of Economics, 108(3): 551-575.

Kreutz, Joakim. 2010. How and When Armed Conflicts End: Introducing the UCDP Conflict Termination Dataset. Journal of Peace Research, 47(2): 243-250.

Montalvo, J.G., Reynal-Querol, M., 2005. Ethnic Polarization, Potential Conflict, and Civil Wars. The American Economic Review 796.

Reynal-Querol, Marta. 2002. Ethnicity, Political Systems, and Civil War. Journal of Conflict Resolution, 46(1): 29-54.

Sambanis, Nicholas. 2001. Do Ethnic and Non-ethnic Civil Wars have the Same Causes? A Theoretical and Empirical Inquiry (Part I). Journal of Conflict Resolution, 45(3): 259282.

Singh, P., Shemyakina, O.N., 2016. Gender-differential effects of terrorism on education: The case of the 1981-1993 Punjab insurgency. Economics of Education Review. doi:10.1016/j.econedurev.2016.02.003

Shemyakina, O. 2011. The effect of armed conflict on accumulation of schooling: Results from Tajikistan. Journal of Development Economics, 95(2), 186-200.

Swee, E.L. 2009. On war and schooling attainment: The case of Bosnia and Herzegovina. HiCN Working Paper 57. 
Uppsala Conflict Data Program (Date of retrieval: 14/07/16) UCDP Conflict Encyclopedia. Available online at: www.ucdp.uu.se/database, Uppsala University.

Weinstein, Jeremy. 2007. Inside Rebellion: The Politics of Insurgent Violence. Cambridge: Cambridge University Press.

Walsh, M. 2000. Aftermath: The impact of conflict on women in Bosnia and Herzegovina. Center for Development Information and Evaluation USAID Working Paper 302, July http://www.peacewomen.org/assets/file/Resources/Academic/ wps_aftermaththeimpactofconflictonwomeninbandh_cdie_2000.pdf. 
Figures and Tables

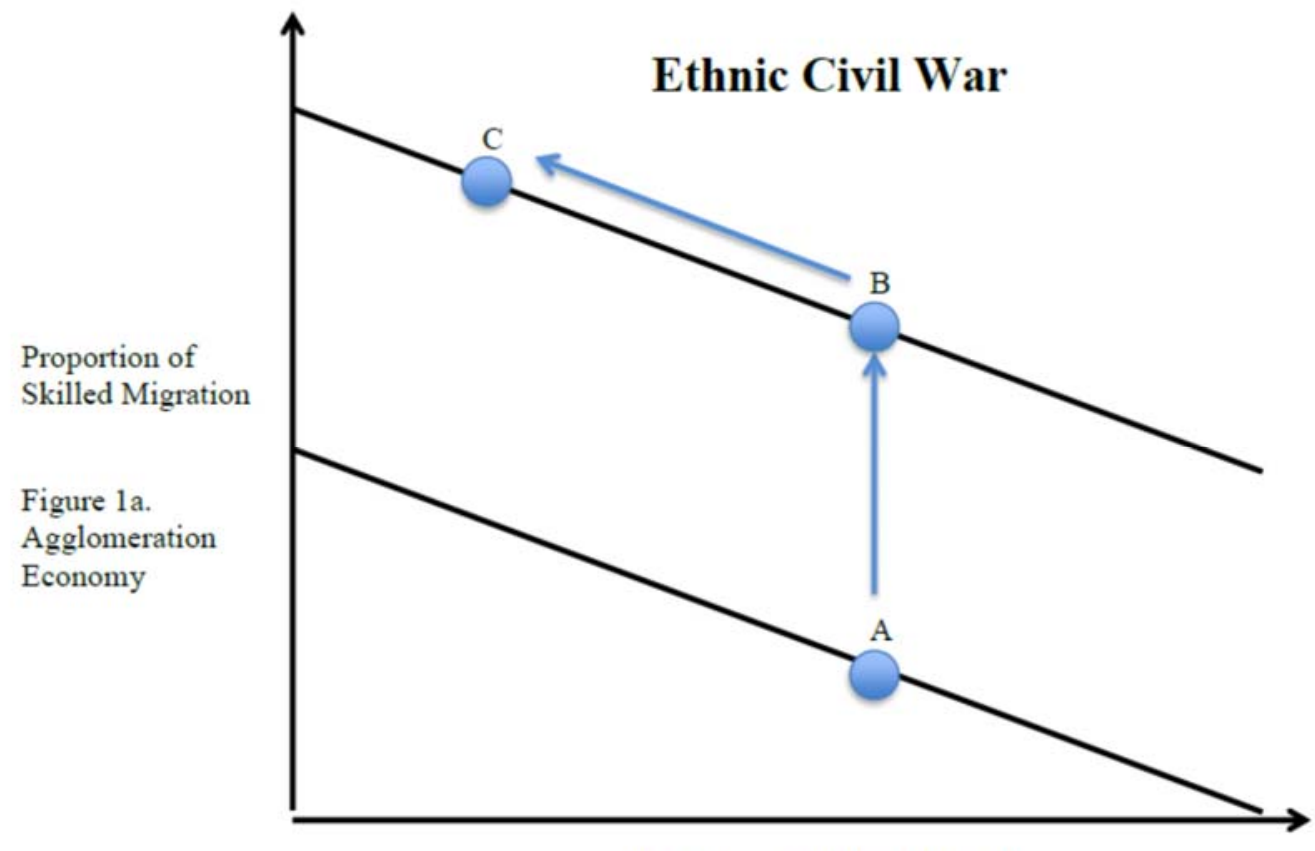

Proportion of Educated People

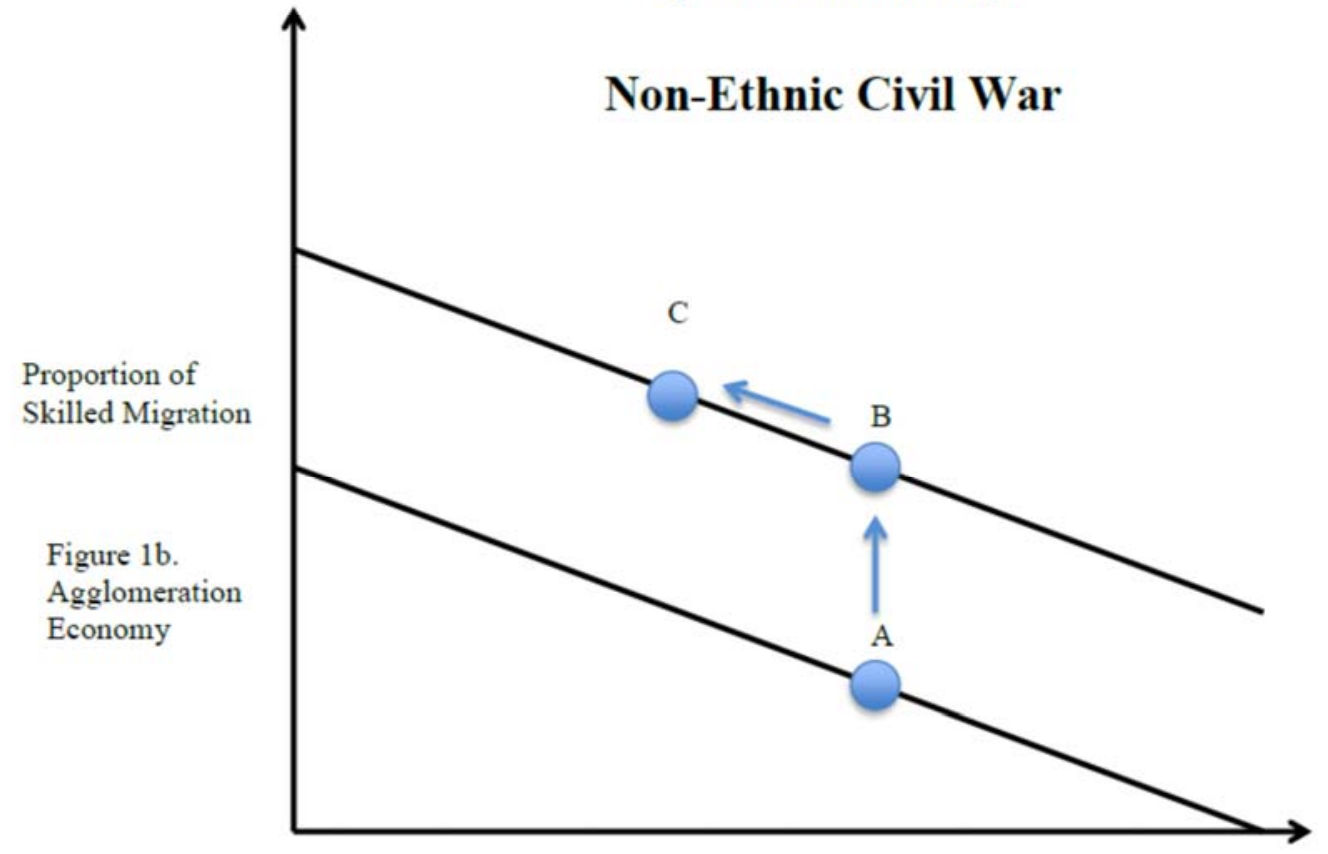

Proportion of Educated People 

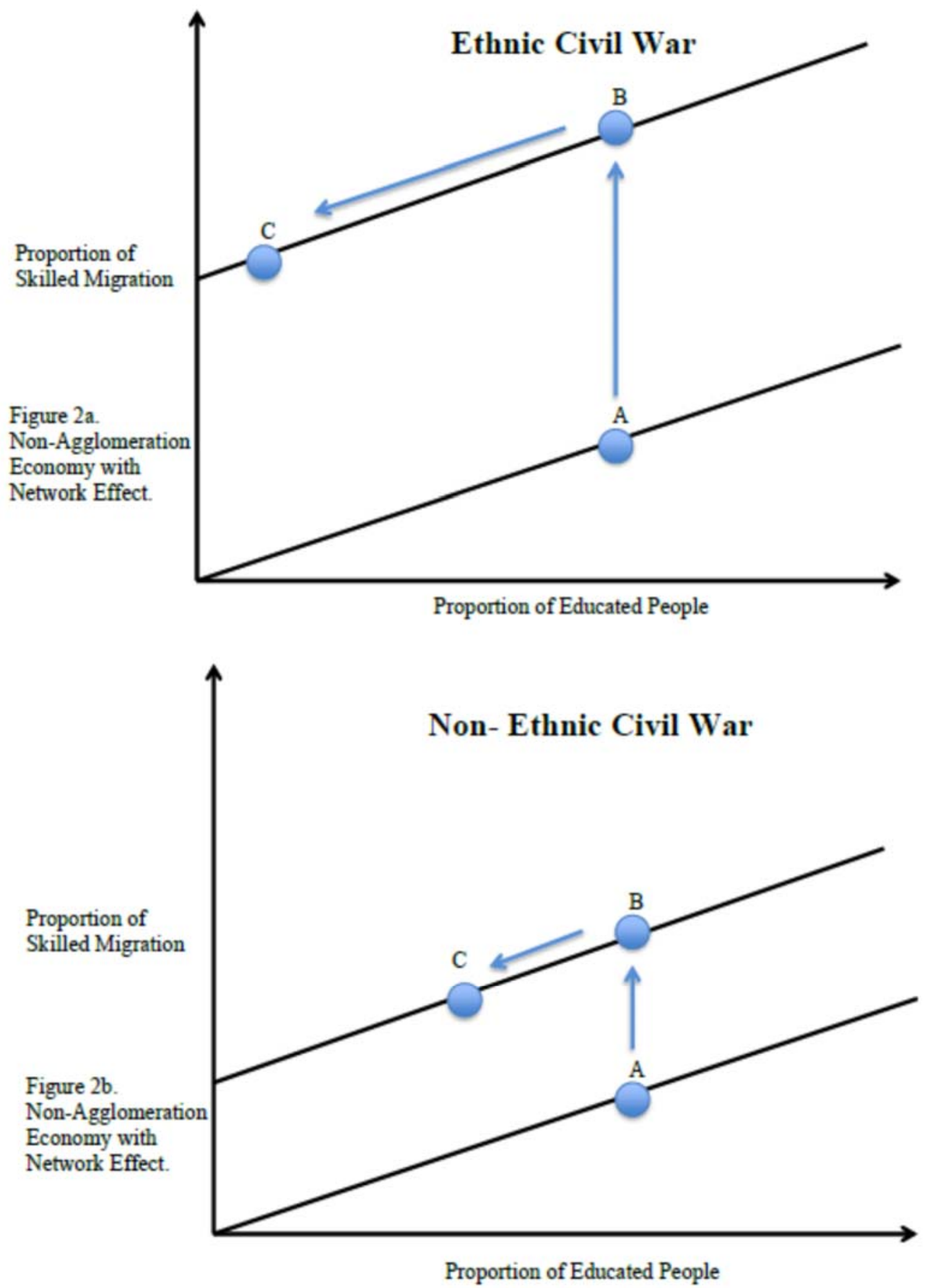
Table 1: Descriptive Statistics

\section{Variables}

Proportion of high-skill emigrants

Total emigrants (ten thousands)

GDP per capita

Conflict (UCDP)

Ethnic conflict (UCDP)

Non-ethnic conflict (UCDP)

Conflict (PITF)

Ethnic conflict (PITF)

Non-ethnic conflict (PITF)

Conflict (COW)

Population (millions)

Polity Index

President

Premier

Military executive

"Other" executive

Assembly-elected president

Parliamentary
Average years of education

\begin{tabular}{cccc}
\hline Mean & Std. Dev & Min & Max \\
\hline 0.375 & 0.159 & 0.015 & 0.867 \\
16.518 & 41.028 & 0.001 & 641.114 \\
$9,265.594$ & $15,223.550$ & 50.042 & $122,438.500$ \\
0.192 & 0.394 & 0 & 1 \\
0.132 & 0.339 & 0 & 1 \\
0.068 & 0.251 & 0 & 1 \\
0.157 & 0.364 & 0 & 1 \\
0.110 & 0.313 & 0 & 1 \\
0.051 & 0.220 & 0 & 1 \\
0.117 & 0.321 & 0 & 1 \\
24.623 & 99.859 & 0.008 & $1,262.645$ \\
0.445 & 7.585 & -10 & 10 \\
5.657 & 3.021 & 0 & 13.003 \\
0.492 & 0.500 & 0 & 1 \\
0.318 & 0.466 & 0 & 1 \\
0.056 & 0.231 & 0 & 1 \\
0.059 & 0.236 & 0 & 1 \\
0.139 & 0.346 & 0 & 1 \\
0.314 & 0.464 & 0 & 1 \\
\hline
\end{tabular}

Note: The Polity Index ranges from -10 to 10 , where -10 to -6 indicates an autocracy, -5 to 5 an anocracy, and 6 to 10 a democracy. 
Table 2: Conflict and the brain drain (Dependent variable = Proportion of high-skill emigrants ${ }^{\mathrm{a}}$ )

Conflict

\begin{tabular}{ccccccc}
\hline$(1)$ & $(2)$ & $(3)$ & $(4)$ & $(5)$ & $(6)$ & $(7)$ \\
\hline 0.0115 & 0.0217 & 0.0380 & 0.0166 & 0.0190 & 0.0259 & 0.0215 \\
$(0.0197)$ & $(0.0254)$ & $(0.0248)$ & $(0.0263)$ & $(0.0231)$ & $(0.0212)$ & $(0.0195)$ \\
No & No & No & Yes & Yes & Yes & Yes \\
No & No & No & No & Yes & Yes & Yes \\
No & No & No & No & No & Yes & Yes \\
No & No & No & No & No & No & Yes \\
1069 & 554 & 554 & 554 & 554 & 537 & 537 \\
0.001 & 0.216 & 0.275 & 0.261 & 0.396 & 0.454 & 0.518
\end{tabular}

Year fixed effects

Region fixed effects

Geography controls

Colonial and legal origins

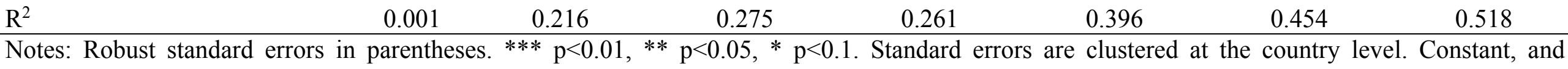

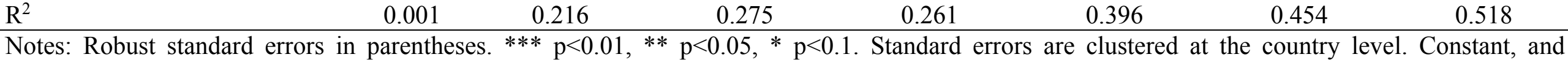

\begin{tabular}{lcccccc}
$\mathrm{R}^{2}$ & 0.001 & 0.216 & 0.275 & 0.261 & 0.396 & 0.454 \\
\hline Notes: Robust standard errors in parentheses. ${ }^{* * *} \mathrm{p}<0.01,{ }^{* *} \mathrm{p}<0.05,{ }^{*} \mathrm{p}<0.1$. Standard errors are clustered at the country level. Constant, and
\end{tabular}

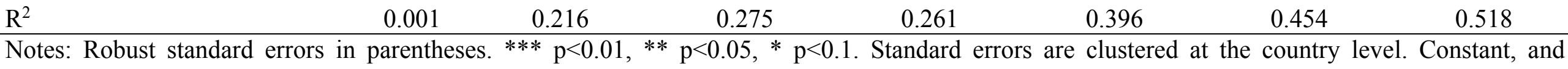
coefficients on year and region dummies are not reported. The Conflict variable, taken from Bang and Mitra (2013), is a dummy that takes the value of 1 if there has been an intrastate war in the past five years in the country and 0 otherwise, and is defined according to the UCDP data. Geography controls include the median latitude and median longitude of each country, as well as a dummy variable for whether the country is landlocked or not. The colonial origins controls include dummy variables on whether the country has been an English or French colony. The legal origins controls include dummy variables on whether the country has an UK, French or German-based legal system. Other controls starting in column (2) include CPI Inflation and Population, Polity Index, executive forms of government (president, premier, military executive, monarchy), and form of government system (presidential, assembly-elected president, parliamentary). Column (3) includes total immigrants as an additional control.

aProportion of high-skill emigrants is defined as the stock of high-skill emigrants divided by the stock of total emigrants from country $i$ in year $t$ living in any of the six main OECD destination countries (the United States, Canada, Australia, France, Germany, and the UK). High-skill emigrants are defined as those with a tertiary qualification (13 or more years of education). See Defoort (2008). 
Table 3: Ethnic conflict and the brain drain (Dependent variable = Proportion of high-skill emigrants ${ }^{\mathrm{a}}$ )

Ethnic conflict

Non-ethnic conflict

Year fixed effects

Region fixed effects

Geography controls

Colonial and legal origins

Observations

$\mathrm{R}^{2}$

\begin{tabular}{ccccccc}
\hline$(1)$ & $(2)$ & $(3)$ & $(4)$ & $(5)$ & $(6)$ & $(7)$ \\
\hline 0.0196 & 0.0190 & 0.0427 & 0.0113 & 0.0183 & 0.0196 & 0.0106 \\
$(0.0259)$ & $(0.0353)$ & $(0.0349)$ & $(0.0364)$ & $(0.0323)$ & $(0.0297)$ & $(0.0271)$ \\
0.0012 & 0.0348 & 0.0343 & 0.0369 & 0.0320 & $0.0411^{*}$ & $0.0410^{* *}$ \\
$(0.0237)$ & $(0.0261)$ & $(0.0251)$ & $(0.0273)$ & $(0.0257)$ & $(0.0227)$ & $(0.0187)$ \\
No & No & No & Yes & Yes & Yes & Yes \\
No & No & No & No & Yes & Yes & Yes \\
No & No & No & No & No & Yes & Yes \\
No & No & No & No & No & No & Yes \\
1069 & 554 & 554 & 554 & 554 & 537 & 537 \\
0.002 & 0.217 & 0.277 & 0.263 & 0.398 & 0.455 & 0.520 \\
\hline
\end{tabular}

coefficients on year and region dummies are not reported. The Ethnic and Non-ethnic conflict variables are taken from Bang and Mitra (2013), who coefficients on year and region dummies are not reported. The Ethnic and Non-ethnic conflict variables are taken from Bang and Mitra (2013), who
apply the identification criterion of Fearon and Laitin to disaggregate the UCDP dataset. Conflict variables are dummies that take the value of 1 if there has been an ethnic or non-ethnic intrastate war in the past five years in the country and 0 otherwise. Geography controls include the median latitude and median longitude of each country, as well as a dummy variable for whether the country is landlocked or not. The colonial origins controls include dummy variables on whether the country has been an English or French colony. The legal origins controls include dummy variables on whether the country has an UK, French or German-based legal system. Other controls starting in column (2) include CPI Inflation and Population, Polity Index, executive forms of government (president, premier, military executive, monarchy), and form of government system (presidential, assembly-elected

executive forms of government (president, premier, military executive, monarchy), and
president, parliamentary). Column (3) includes total immigrants as an additional control.

aProportion of high-skill emigrants is defined as the stock of high-skill emigrants divided by the stock of total emigrants from country $i$ in year $t$ living in any of the six main OECD destination countries (the United States, Canada, Australia, France, Germany, and the UK). High-skill emigrants are defined as those with a tertiary qualification (13 or more years of education). See Defoort (2008). 
Table 4: Ethnic conflict and the brain drain (Dependent variable = Proportion of high-skill emigrants ${ }^{\mathrm{a}}$ )

\section{Conflict}

Ethnic conflict

Year fixed effects

Region fixed effects

Geography controls

Colonial and legal origins

Observations

$\mathrm{R}^{2}$ the identification criterion of Fearon and Laitin to disaggregate the UCDP dataset. Conflict variables are dummies that take the value of 1 if there has been an intrastate or ethnic intrastrate war in the past five years in the country and 0 otherwise. Geography controls include the median latitude and median longitude of each country, as well as a dummy variable for whether the country is landlocked or not. The colonial origins controls include dummy variables on whether the country has been an English or French colony. The legal origins controls include dummy variables on whether the country has an UK, French or Germon-based legal systm. Other controls starting in column (2) include CPI Inflation and Population, Polity Ind executive forms of government (president, premier, military executive, monarchy), and form of government system (presidential, assembly-elected president, parliamentary). Column (3) includes total immigrants as an additional control.

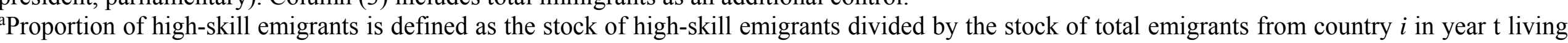
in any of the six main OECD destination countries (the United States, Canada, Australia, France, Germany, and the UK). High-skill emigrants are defined as those with a tertiary qualification (13 or more years of education). See Defoort (2008). 
Table 5: Ethnic conflict and the brain drain (Dependent variable = Proportion of medium-skill emigrants ${ }^{\mathrm{a}}$ )

\section{Conflict}

Ethnic conflict

Year fixed effects

Region fixed effects

Geography controls

Colonial and legal origins

Observations

$\mathrm{R}^{2}$

\begin{tabular}{ccccccc}
\hline$(1)$ & $(2)$ & $(3)$ & $(4)$ & $(5)$ & $(6)$ & $(7)$ \\
\hline 0.0102 & $0.0391^{*}$ & $0.0391^{*}$ & $0.0443^{* *}$ & 0.00953 & 0.0156 & 0.0144 \\
$(0.0206)$ & $(0.0226)$ & $(0.0226)$ & $(0.0221)$ & $(0.0141)$ & $(0.0126)$ & $(0.0129)$ \\
$-0.0511^{* *}$ & $-0.0628^{* *}$ & $-0.0628^{* *}$ & $-0.0620^{* *}$ & -0.00987 & -0.0159 & -0.0126 \\
$(0.0232)$ & $(0.0268)$ & $(0.0270)$ & $(0.0262)$ & $(0.0176)$ & $(0.0151)$ & $(0.0151)$ \\
No & No & No & Yes & Yes & Yes & Yes \\
No & No & No & No & Yes & Yes & Yes \\
No & No & No & No & No & Yes & Yes \\
No & No & No & No & No & No & Yes \\
1072 & 554 & 554 & 554 & 554 & 537 & 537 \\
0.020 & 0.154 & 0.154 & 0.224 & 0.551 & 0.603 & 0.624 \\
\hline
\end{tabular}

coefficients on year and region dummies are not reported. The Conflict and Ethnic conflict variables are taken from Bang and Mitra (2013), who apply the identification criterion of Fearon and Laitin to disaggregate the UCDP dataset. Conflict variables are dummies that take the value of 1 if there has been an intrastate or ethnic intrastrate war in the past five years in the country and 0 otherwise. Geography controls include the median latitude and median longitude of each country, as well as a dummy variable for whether the country is landlocked or not. The colonial origins controls include dummy variables on whether the country has been an English or French colony. The legal origins controls include dummy variables on whether the country has an UK, French or German-based legal system. Other controls starting in column (2) include CPI Inflation and Population, Polity Index, executive forms of government (president, premier, military executive, monarchy), and form of government system (presidential, assembly-elected president, parliamentary). Column (3) includes total immigrants as an additional control.

aProportion of medium-skill emigrants is defined as the stock of medium-skill emigrants divided by the stock of total emigrants from country $i$ in year $t$ living in any of the six main OECD destination countries (the United States, Canada, Australia, France, Germany, and the UK). Medium-skill emigrants are defined as those with a secondary qualification (9-12 years of education). See Defoort (2008). 
Table 6: Ethnic conflict and the brain drain (Dependent variable = Proportion of low-skill emigrants ${ }^{\mathrm{a}}$ )

Conflict

\begin{tabular}{ccccccc}
\hline$(1)$ & $(2)$ & $(3)$ & $(4)$ & $(5)$ & $(6)$ & $(7)$ \\
\hline-0.0015 & -0.0461 & -0.0463 & -0.0569 & -0.0236 & -0.0420 & $-0.0449^{*}$ \\
$(0.0341)$ & $(0.0358)$ & $(0.0342)$ & $(0.0362)$ & $(0.0324)$ & $(0.0288)$ & $(0.0252)$ \\
0.0141 & 0.0486 & 0.0270 & 0.0578 & 0.00443 & 0.0203 & 0.0287 \\
$(0.0443)$ & $(0.0531)$ & $(0.0525)$ & $(0.0533)$ & $(0.0506)$ & $(0.0443)$ & $(0.0392)$ \\
No & No & No & Yes & Yes & Yes & Yes \\
No & No & No & No & Yes & Yes & Yes \\
No & No & No & No & No & Yes & Yes \\
No & No & No & No & No & No & Yes \\
1073 & 554 & 554 & 554 & 554 & 537 & 537 \\
0.001 & 0.153 & 0.187 & 0.207 & 0.377 & 0.434 & 0.474 \\
\hline
\end{tabular}

Year fixed effects

Region fixed effects

Geography controls

Colonial and legal origins

Observations

0.00

0.207

0.377

Notes: Robust standard errors in parentheses. ${ }^{* *} \mathrm{p}<0.01,{ }^{* *} \mathrm{p}<0.05, * \mathrm{p}<0.1$. Standard errors are clustered at the country level. Constant, and coefficients on year and region dummies are not reported. The Conflict and Ethnic conflict variables are taken from Bang and Mitra (2013), who apply the identification criterion of Fearon and Laitin to disaggregate the UCDP dataset. Conflict variables are dummies that take the value of 1 if there has been an intrastate or ethnic intrastrate war in the past five years in the country and 0 otherwise. Geography controls include the median latitude and median longitude of each country, as well as a dummy variable for whether the country is landlocked or not. The colonial origins controls include dummy variables on whether the country has been an English or French colony. The legal origins controls include dummy variables on whether the country has an UK, French or German-based legal system. Other controls starting in column (2) include CPI Inflation and Population, Polity Index, executive forms of government (president, premier, military executive, monarchy), and form of government system (presidential, assembly-elected president, parliamentary). Column (3) includes total immigrants as an additional control.

${ }^{a}$ Proportion of low-skill emigrants is defined as the stock of low-skill emigrants divided by the stock of total emigrants from country $i$ in year $t$ living in any of the six main OECD destination countries (the United States, Canada, Australia, France, Germany, and the UK). Low-skill emigrants are defined as those with a primary-level education (0-8 years of education). See Defoort (2008). 
Table 7: Ethnic conflict in non-agglomerating economy (Dependent variable = Average years of education)

Ethnic Conflict

Year fixed effects

Region fixed effects

Geography controls

Colonial and legal origins

Observations

$\mathrm{R}^{2}$

unt standard errors in parentheses. $* * *$ p<0.01, $0.41 \%$

p $0.01, \quad p<0.05, * p<0.1$. Standard errors are clustered at the country level. (2013), and coefficients on year and region dummies are not reported. The Ethnic conflict variable is taken from Bang and Mitra dummy that takes the value of 1 if there has been an ethnic intrastate war in the past five years in the country and 0 otherwise. Geography controls include the median latitude and median longitude of each country, as well as a dummy variable for whether the country is landlocked or not. The colonial origins controls include dummy variables on whether the country has been an English or French colony. The legal origins controls include dummy variables on whether the country has an UK, French or German-based legal system. Other controls starting in Column (2) include Polity Index, executive forms of government (president, premier, military executive, monarchy), and form of government system (presidential, assembly-elected president, parliamentary). 
Table 8: Non-ethnic conflict in non-agglomerating economy (Dependent variable = Average years of education)

Non-Ethnic Conflict

Year fixed effects

Region fixed effects

Geography controls

Colonial and legal origins

Observations

$\mathrm{R}^{2}$

\begin{tabular}{cccccc}
$(1)$ & $(2)$ & $(3)$ & $(4)$ & $(5)$ & $(6)$ \\
\hline$-1.627^{* * *}$ & $-0.847^{* *}$ & $-0.859^{* *}$ & $-0.748^{* *}$ & $-0.784^{*}$ & -0.512 \\
$(0.459)$ & $(0.409)$ & $(0.414)$ & $(0.332)$ & $(0.404)$ & $(0.344)$ \\
No & No & Yes & Yes & Yes & Yes \\
No & No & No & Yes & Yes & Yes \\
No & No & No & No & Yes & Yes \\
No & No & No & No & No & Yes \\
864 & 724 & 724 & 724 & 697 & 697 \\
0.022 & 0.392 & 0.438 & 0.671 & 0.421 & 0.554 \\
\hline ses. $* * *$ & $\mathrm{p}<0.01, * *$ & $\mathrm{p}<0.05, * \mathrm{p}<0.1$. Standard errors are clustered at the country level.
\end{tabular}

Constant, and coefficients on year and region dummies are not reported. The Non-ethnic conflict variable is taken from Bang and Mitra (2013), who apply the identification criterion of Fearon and Laitin to disaggregate the UCDP dataset. The conflict variable is a dummy that takes the value of 1 if there has been an ethnic intrastate war in the past five years in the country and 0 otherwise. Geography controls include the median latitude and median longitude of each country, as well as a dummy variable for whether the
country is landlocked or not. The colonial origins controls include dummy variables on whether the country has been an English or French colony. The legal origins controls include dummy variables on whether the country has an UK, French or German-based legal system. Other controls starting in Column (2) include Polity Index, executive forms of government (president, premier, military executive, monarchy), and form of government system (presidential, assembly-elected president, parliamentary). 